\title{
Determination of cracking causes in building structural elements
}

\author{
Valentina Halushko, Alexandr Meneiliuk*, Stanislav Kyryliuk \\ Odessa State Academy of Civil Engineering and Architecture, 65029, Odessa, Ukraine
}

\begin{abstract}
The article deals with the problems of buildings built many years ago, in which current and major repairs were not carried out in an appropriate manner. At the same time, buildings experience various deformations, such as yield, heel, subsidence, deflections, bends, twists, distortions, horizontal displacements. The survey of residential buildings built in the $80 \mathrm{~s}$ is described and the analysis of the results of the survey of one of these buildings is carried out. The theoretical problem of the distribution of moisture in depth and various degrees of soil moisture has been solved. The reasons for the appearance of cracks in structures and cracks between individual building elements are also determined. The survey of a 9-storey brick residential building, built in the late $80 \mathrm{~s}$, which is in the period of normal operation, is considered. At the same time, the considered building is operated with significant deviations from regulatory requirements. The causes of cracks in individual structures and cracks between individual elements in the building are found. The problem of the distribution of moisture in depth with local soaking is solved on the basis of a numerical method, and the character of soil moistening at different depths with different degrees of moistening and characteristics of the base soil is obtained.
\end{abstract}

\section{Introduction}

There is a huge number of buildings built many years ago on the territory of Ukraine and other post-Soviet states. In most of them, maintenance and overhaul repairs were not carried out properly. Many buildings have damages in the form of cracks in structures and gaps between them, or individual building elements.

For high-quality repairs and normal operation of such buildings in the future, it is necessary to determine the reasons for the destruction of buildings' structures in order to eliminate them before the forthcoming repair.

Eliminating the causes will avoid the recurrence of cracks and additional costs for extraordinary repairs.

The study of information sources made it possible to identify authors whose results of work are close to the research topic. This is [1-3, 5, 7-15]. The analysis of these works made it possible to determine the following types of deformations in buildings: yield, heel, subsidence, deflections, bends, twists, distortions, horizontal displacements [3, 6].

${ }^{*}$ Corresponding author: meneilyk@gmail.com 
Each of them is discussed below.

- Building yield occurs when the soil under the foundation is compacted. Precipitation is caused by landslides, karst and seismic phenomena, and traffic. Yield is a danger signal sent by unstable ground or weak foundations. Uniform yield of the foundation sole does not cause structural violations, but complicates the operation of the building. Uneven yield and vertical displacement of part of the building can lead to destruction.

- When the soil under the building is heterogeneous, or the load on it is uneven, when the soils move or skew occurs, then cracks and faults appear. When cracks are caused by building yield, they can open and close when exposed to temperature. The most dangerous are through cracks in load-bearing beams, ceilings, foundations.

- Constant crosswind, ground pressure, water pressure cause displacement of structures and constructions. The higher the building, the stronger the wind load. Towers, scaffolds, chimneys are exposed to wind and solar heat, which cause bending and twisting.

- Rolls occur in rigid structures due to the asymmetric loading of the base and develop in two opposite directions.

- In objects without sufficient rigidity, bending and deflection occur under the influence of abrupt settlement. The danger zone during deflection is the lower part of the structure. When bent - the top one.

Among the main causes of deformations, the authors highlight the following: design errors; poor quality or incorrect production technology; using materials that do not meet standards; improper redevelopment during operation; uneven building yield.

The latter can be caused by a change in soil conditions, the absence or timely repair of the building (utilities, blind area around the building, roof).

Therefore, the purpose of the work is to determine the causes of cracks and gaps in structural elements and between individual elements in the building being inspected.

To meet the purpose, the following tasks have been solved in the article:

1. an analysis of the literature on the topic of research is carried out;

2. a survey of residential buildings built in the $80 \mathrm{~s}$ and an analysis of the results of a survey of one of such buildings were carried out;

3. a theoretical problem of the distribution of moisture content in depth and various degrees of soil moisture has been solved;

4. the reasons for the appearance of cracks in structures and cracks between individual building elements are determined.

\section{Research methods}

The following methods were used in the work: visual and instrumental examination of the technical condition of the building; numerical methods for solving problems; theoretical studies to determine moisture content at different depths with different soil characteristics and local soaking; system analysis in the analysis of literature, and the method of generalization in the analysis of results.

The building survey consisted of several stages:

- First stage - examination of general condition;

- Second stage is a detailed inspection of the object.

- Third stage is laboratory research.

- Fourth stage is a generalization of all examination results of possible studies, summing up.

\section{Results}


The authors took part in a survey of a number of buildings built in the $80 \mathrm{~s}$. In some of them, significant destruction of structures and crack opening widths from several millimeters to several centimeters were revealed.

As an example, consider a residential building on the Balkovskaya street, city of Odessa. Residential 9 - storey brick building, built in the late 80 s, in a period of normal use.

Number of floors 9, floor height: 2.8 m, number of apartments: 216 (Fig. 1).

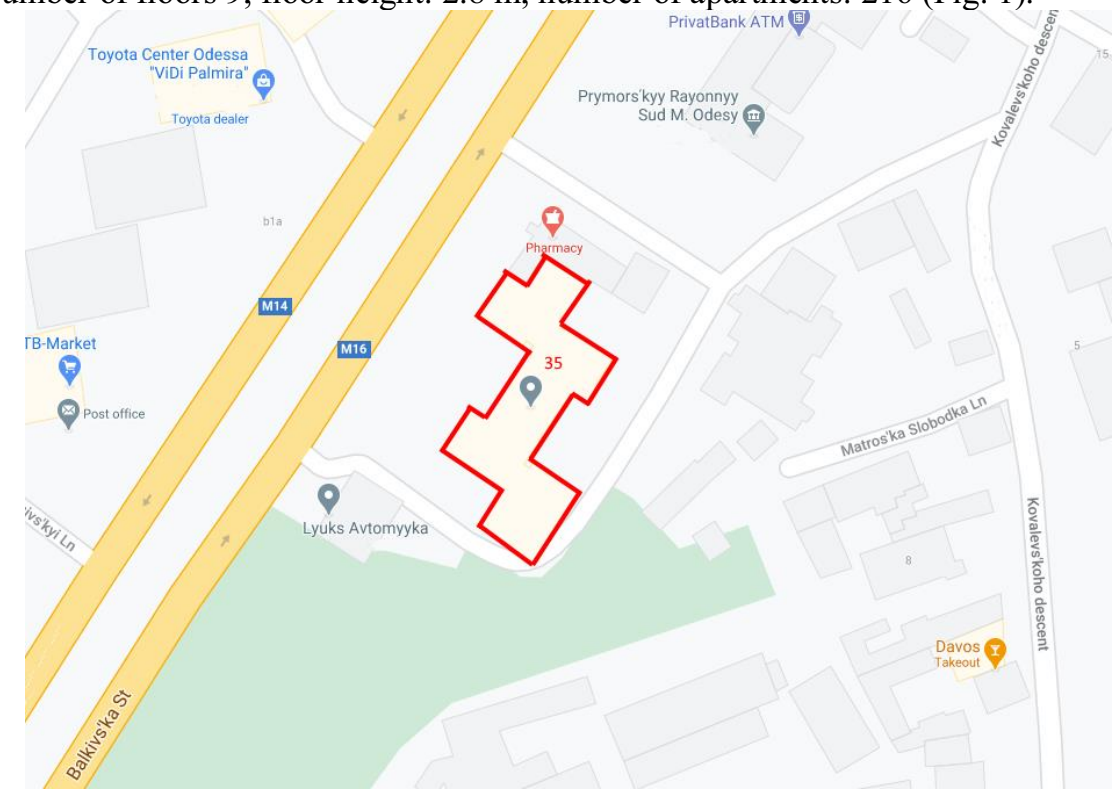

Fig. 1. Building location plan

The surveyed building belongs to the first group of capital "Especially capital", with a standard durability of 150 years. The building is made of bricks, the floors are reinforced concrete ribbed slabs, the roof is flat roll. The surveyed object was put into operation in 1989. The building is in the period of normal operation. Judging by the external examination, the building was erected without visible signs of errors in design and construction.

In accordance with the current standards, the inspected residential building by now had to go through 5 cycles of current repair measures with a mandatory increase in the moisture resistance of facades, revision and repair of wall fencing, cosmetic repairs of entrances, repair of flat industrial coatings. In 2014, it had to undergo a complete overhaul as part of the following measures: change of all utilities, restoration of the blind area, change of all window and door fillings, strengthening of balconies and canopies.

Instead, the residents' funds were used to replace the roof, partially insulate the facade, replace the elevator motor and restore the stairs.

During the current repair activities,:

$\checkmark$ sealing cracks, painting the walls of stairwells;

$\checkmark$ repair of stairrailings;

$\checkmark$ whitewashing of ceilings.

Thus, it can be concluded that during the period of normal operation, the structure is operated with significant deviations from regulatory requirements. Fig. 2 - 6 show photographs of the state of the walls of the building, both from the inside and from the outside.

During the external examination of the structure, longitudinal and transverse cracks in the blind area were found, the width of which reaches $1 \mathrm{~cm}$ in places, as well as cracks in 
the seams between the basement blocks and along the brickwork of the building wall up to several centimeters wide (Fig. 2-6).
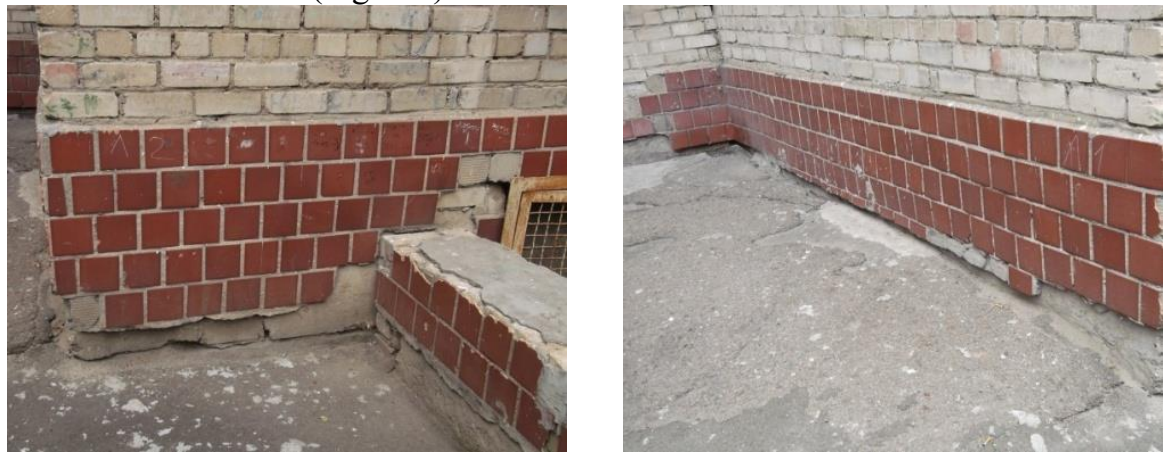

Fig. 2. Photo fragment of the destruction of the basement and blind area

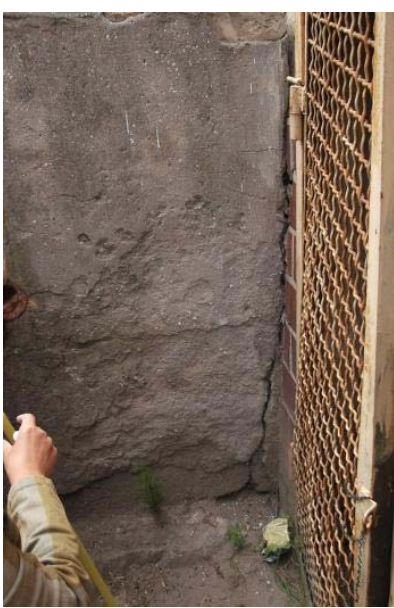

Fig. 3. Cracks in the seams between base blocks

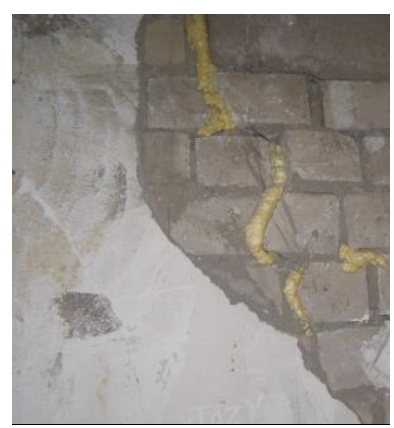

Fig. 5. Cracks along the inner walls of the building
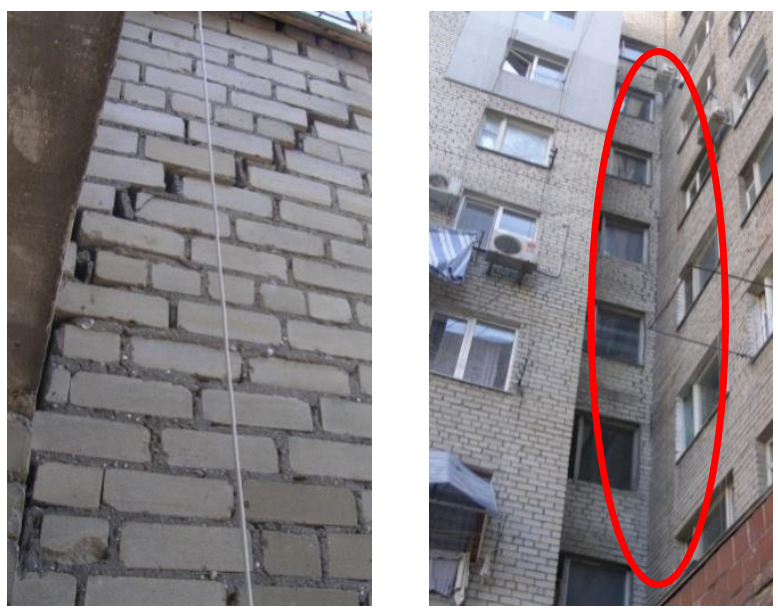

Fig. 4.Cracks along the outer walls of the building typical for uneven settlement (up to $3 \mathrm{~cm}$ wide)

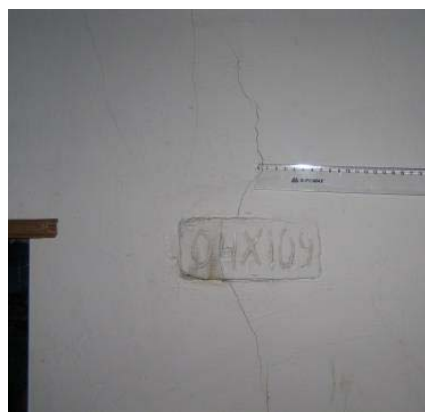

Fig. 6. Crack watching mark

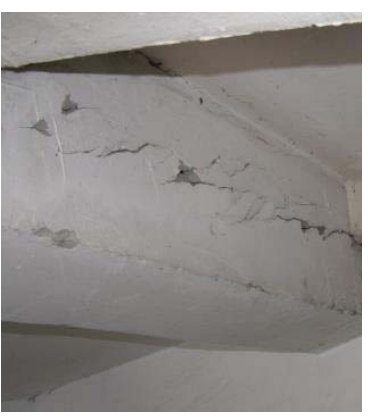

Fig. 7. Displacement of the flight of stairs from the design marks by $3-5 \mathrm{~cm}$ characteristic of uneven settlement 

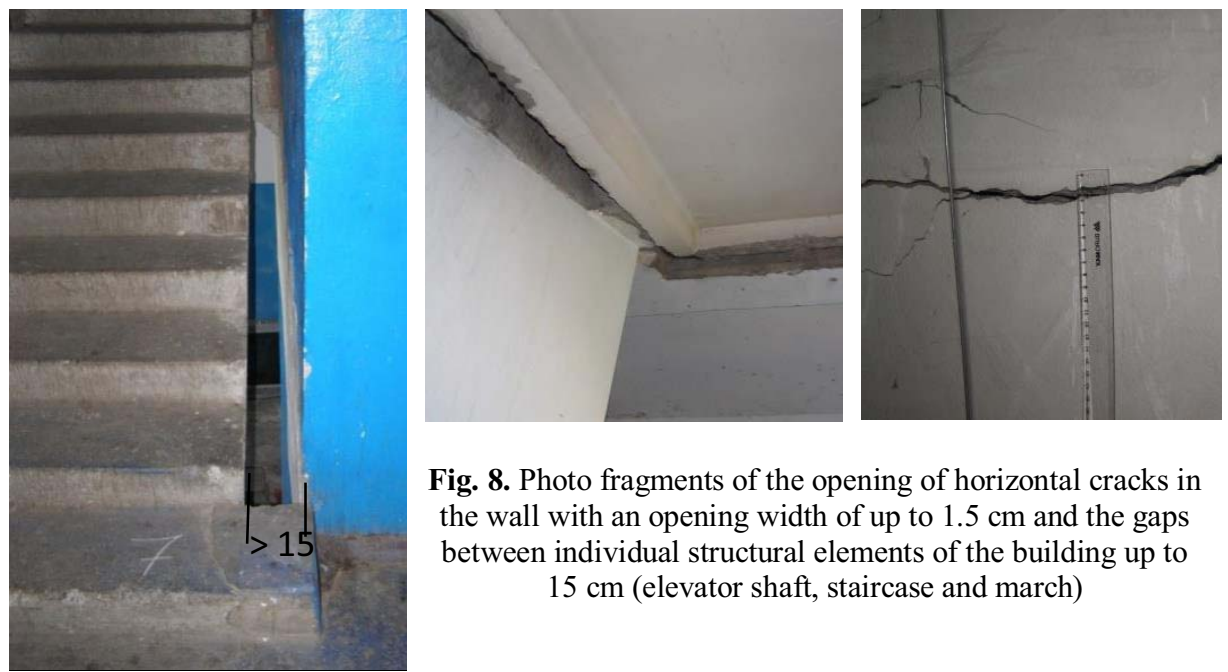

Fig. 8. Photo fragments of the opening of horizontal cracks in the wall with an opening width of up to $1.5 \mathrm{~cm}$ and the gaps between individual structural elements of the building up to $15 \mathrm{~cm}$ (elevator shaft, staircase and march)

Considering the condition of the blind area, it is safe to say that it does not cope with its purpose and water seeps into the ground under the foundation. Another reason is the constant pinpoint leaks in the water and sewer pipes that are laid in the basement of the building. Fig. 9 shows a plan of the location of pipes in the basement, indicating the places where leaks of communications were detected. Leaks in communications undoubtedly lead to local soaking of soil foundations under the foundations of buildings in these places. In addition to leaks of engineering networks, during the inspection of the building, local damage to the blind area and basement was found (Fig. 2). It will also undoubtedly lead to periodic soaking of the subgrade in these locations.

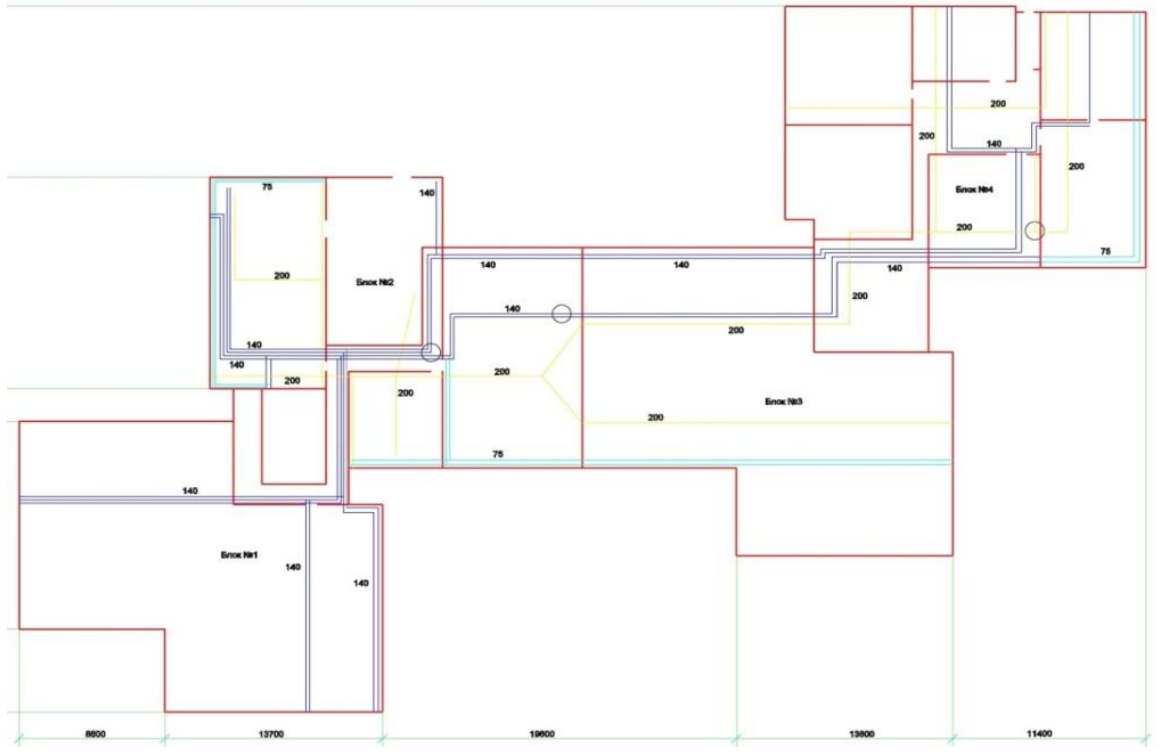

Fig. 9. Layout of water and sewer pipes with leak marks (conventional circles)

Fig. 9, 10 show leaks of water and sewer pipes, which were found in 3 places (highlighted in a circle on the plan). For a long time, the water washed away the soil in the basement and destroyed the compacted soil structure under the building itself. 
It can be assumed that as a result of this, an uneven settlement of the foundation occurred and sedimentary cracks formed in individual structures and gaps between the elements of buildings.
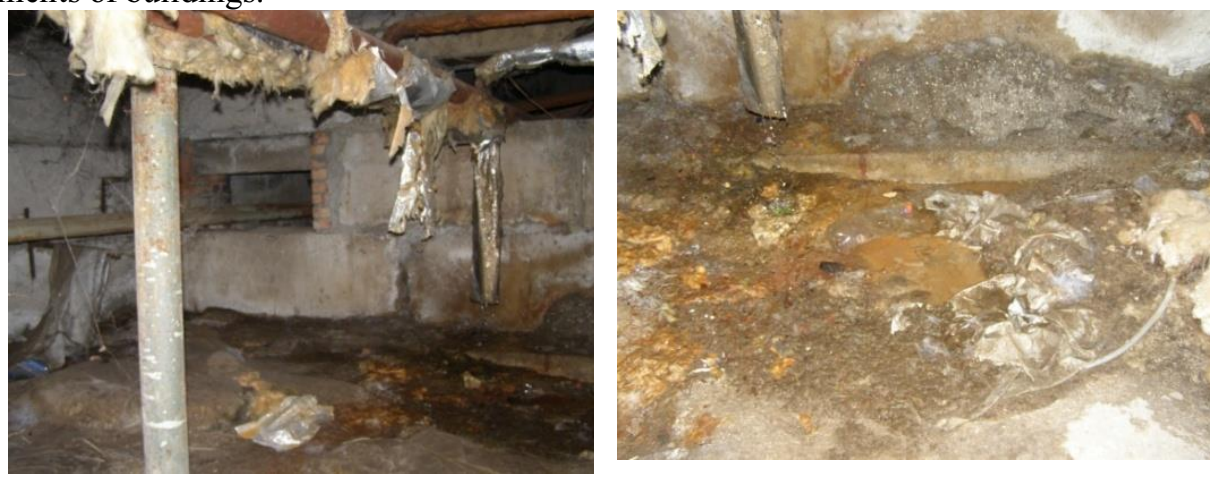

Fig. 10. Photo fragment of a sewer pipe leak

Analysis of information sources showed that one of the causes of cracks in individual structures and cracks between individual elements in a building is flooding of the territory. Depending on the type of building, cracks and gaps can reach $10-15 \mathrm{~cm}$, and sometimes even more.

Leaks from water-carrying utilities can have a significant impact on the condition of buildings. And as a result - the soaking of the base soils. Indeed, with leaks in the basements of houses, water accumulates, which can cause deformation of the soil of the building.

Let's try to establish the regularities of the process of local soaking theoretically $[5,11]$.

The authors considered it necessary to study the nature of this type of soil moisture based on a numerical method.

In order to study the dynamics of soil moistening, one of the equations was used, the results of which are presented below.

With incomplete water saturation of the soil, in the case of one-dimensional moistening, we obtain the equation of soil saturation in the following form

$$
\frac{\partial W}{\partial t}=\frac{\partial}{\partial y} \cdot\left[K(W) \cdot \frac{\partial f(W)}{\partial y}\right]-\frac{\partial K(W)}{\partial y}
$$

where $f(W)=\frac{R_{k}(W)}{j_{W}} ; K(W)=K_{\phi}(a+b W)^{c} ; \quad P_{\kappa}=-\alpha+\beta W$;

$$
a=-\frac{U}{n-U} ; \quad b=\frac{1}{n-U},
$$

where $P_{\kappa^{-}}$capillary pressure;

$\alpha$ and $\beta$ - constants determined experimentally;

$$
\begin{array}{ll}
K_{\phi} & \text { - filtration coefficient; } \\
W & \text { - soil moisture; } \\
v & \text { - amount of cohesive moisture; } \\
n & \text { - soil porosity; } \\
j_{w} & \text { - specific gravity of water; } \\
c & -3.56 \text { according to S.F. Averyanov. }
\end{array}
$$

Equation (1) coincides with the equation of N.N. Verigin and A.Klut. It was investigated in detail by J. Philip.

By linearization and the small parameter method with the subsequent use of the Laplace transform in the work, the solution of equation (1) is obtained in the following form 


$$
W(y, t)=W_{0}+\frac{W_{n}-W_{0}}{2} \cdot\left[\exp (2 \xi) \cdot \operatorname{erfc}\left(\frac{\xi}{2 \sqrt{\tau}}+\sqrt{\tau}\right)+\operatorname{erfc}\left(\frac{\xi}{2 \sqrt{\tau}}-\sqrt{\tau}\right)\right]
$$

where $_{\operatorname{erfc}}(x)=\frac{2}{\sqrt{\pi}} \int_{x}^{\infty} e^{-p^{2}} d p ; \tau=\frac{\ell^{2} t}{4 x} ; \xi=\frac{\ell y}{2 x} ; x=K_{\phi}\left(a+b W_{0}\right)^{c} f^{\prime}\left(W_{0}\right)$;

$\ell=K_{\phi} C \cdot\left(a+b W_{c}\right)^{-1} ; W_{n}=n-v$,

where $W_{0}$ - natural soil moisture;

$W_{n}$-full soil moisture content.

Equation 2 satisfies the experimental data only for a small humidity range, up to 0.15 $\left(\lambda=\mathrm{W}_{\mathbf{n}}-\mathrm{W}_{\mathbf{0}}\right)$.

Equation 1 is adequate to the equation

$$
\frac{\partial W}{\partial t}=C K_{\phi} \cdot(a+b W)^{c-1} \cdot \frac{b \beta}{\gamma_{W}}\left(\frac{\partial W}{\partial y}\right)^{2}-C K_{\phi}(a+b W)^{c-1} b \frac{\partial W}{\partial y}+K_{\phi}(a+b W)^{c} \frac{\beta}{\gamma_{W}} \cdot \frac{\partial^{2} W}{\partial y^{2}}
$$

If we apply the finite-difference approximation of the explicit scheme in time and central differences in space (Fig. 11).

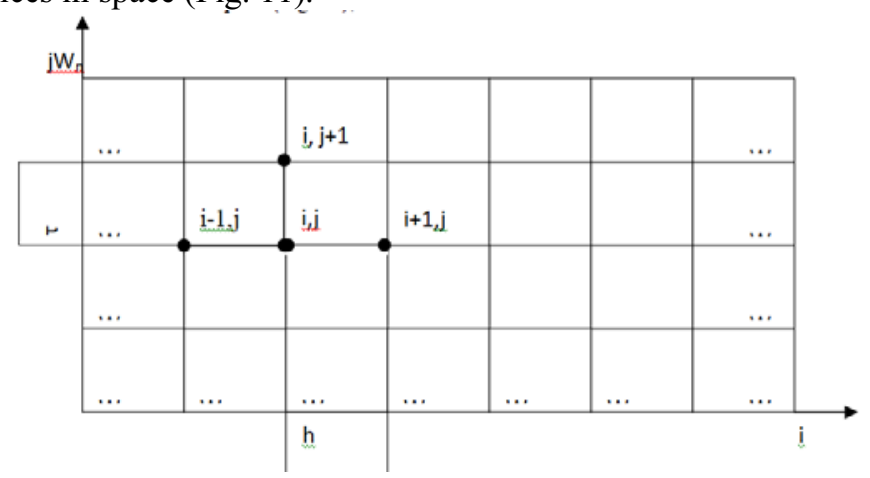

Fig. 11. Finite-difference approximation scheme

then the corresponding difference equation for the node will have the following form:

$$
\begin{aligned}
& W_{j+1}^{i}=W_{j}^{i}+\frac{c b \beta}{\gamma_{W}} \cdot \frac{\tau}{h^{2}} K_{\phi}\left(a+b W_{j}^{i}\right)^{c-1}\left(W_{j}^{i+1}-W_{j}^{i}\right)^{2}- \\
& -W_{j}^{i+1}\left[c b \frac{\tau}{h} K_{\phi}\left(a+b W_{j}^{i}\right)^{c-1}-\frac{\beta}{\gamma_{W}} \cdot \frac{\tau}{h^{2}} K_{\phi}\left(a+b W_{j}^{i}\right)^{c}\right]+ \\
& +W_{j}^{i}\left[c b \frac{\tau}{h} K_{\phi}\left(a+b W_{j}^{i}\right)^{c-1}-\frac{2 \beta}{\gamma_{W}} \cdot \frac{\tau}{h^{2}} K_{\phi}\left(a+b W_{j}^{i}\right)^{c}\right]+ \\
& W_{j}^{i-1} \frac{\beta}{\gamma_{W}} \cdot \frac{\tau}{h^{2}} K_{\phi}\left(a+b W_{j}^{i}\right) c
\end{aligned}
$$

where $\tau$ - time grid step;

$h$ - grid step in space.

A specific application of expression (4) is given for a section of the grid (Fig. 12) with dimensions in depth of $15 \mathrm{~m}$, in time of 20 days under initial and boundary conditions $W(0$; $j)=W_{n} ; W(15 m ; j)=W_{0} ; W(i ; 0)=W_{0}$ 


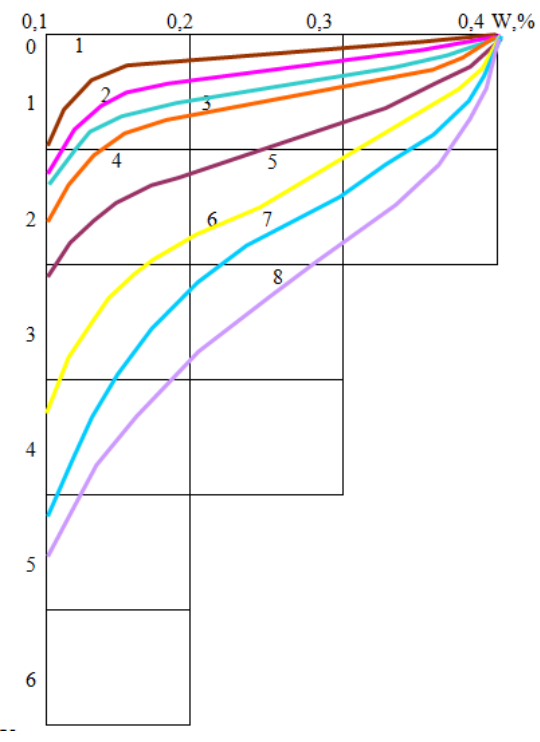

Fig. 12. Dependence of the distribution of moisture content in depth for different durations of soil moistening with the following characteristics: $\mathrm{n}=0,4$ and $\mathrm{Q}=2,4 \mathrm{~m}^{2} /$ day $(1,2,3,4)$; $\mathrm{n}=0,4$ and $\mathrm{Q}=24 \mathrm{~m}^{2} /$ day $(5,6,7,8)$, values: $1-\mathrm{t}=$ 5 day, 2 - 10day, 3 - 15day, 4 -20day.

The soil is homogeneous throughout the thickness with moisture $\mathrm{W}_{\mathrm{o}}=0,1 ; \mathrm{W}_{\mathrm{n}}=0,40$ porosity 0.4 and 0.52 and coefficient of moisture conductivity $\left(Q=K_{\phi} \beta\right) 2,4$ and 24 $\mathrm{m}^{2} /$ day.

The stability of the process of solving equation (4) is achieved by selecting the optimal ratio of steps in time and space. In the work, $\tau=0.02$ days are taken; $h=0.5 \mathrm{~m}$. The performed verification of the convergence of the process by comparing the solutions at different time steps gives a discrepancy not exceeding $10 \%$, which is quite sufficient for practical purposes.

Fig. 13 shows the dependence of the distribution of moisture content over depth for different duration of moisture for soils with characteristics: $n=0,4$ and $Q=2,4 \mathrm{~m}^{2} /$ day $(1$, $2,3,4) ; n=0,4$ and $Q=24 \mathrm{~m}^{2} /$ day $(5,6,7,8)$.

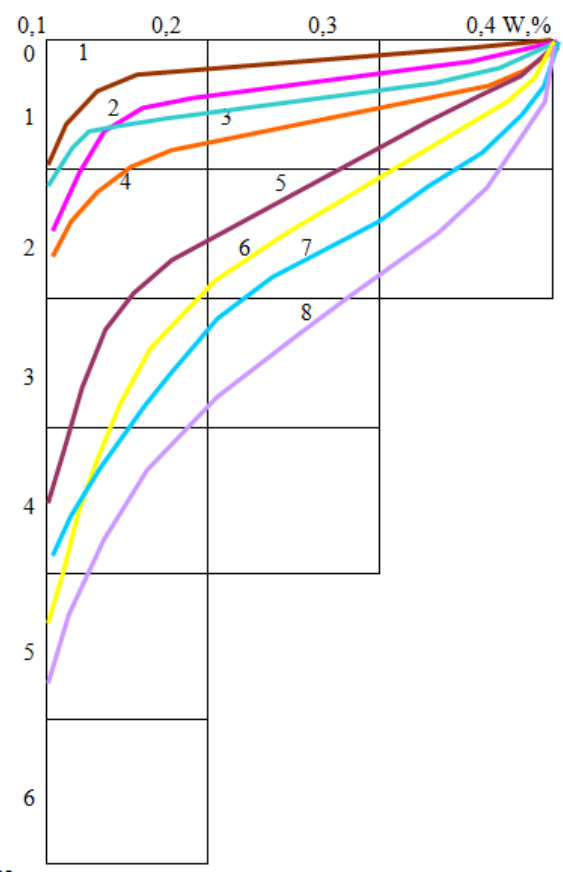

Fig. 13. The dependence of the distribution of moisture in depth on the 20th day from the beginning of moisture, obtained from the data of I.I. Kulabukhova and P. Ya. PolubarinovaKochina $(1,2,5,6)$ and by the numerical method $(3,4,7,8)$ 
In the initial period of moistening, soil moisture increases sharply due to the dominant action of capillary-sorption forces, and then after 15-20 days the process slows down, and further moisture penetration occurs mainly due to gravitational forces. At time $t=\infty$, at all points along the depth, the soil moisture will be equal to its full moisture capacity. The moisture conductivity coefficient of the soil has a significant effect on the nature of moisture.

Comparing the calculation results, for example, on the 20th day (Fig. 10), it can be seen that the shape of the curves is almost the same, but according to the calculation by the numerical method, due to taking into account all nonlinear terms of equation (1), the curve is shifted down by $0.4-0,8 \mathrm{~m}$ from the curve constructed according to I. I. Kulabukhova and P. Ya. Polubarinova-Kochina.

\section{Discussion}

The calculation results indicate the reliability of the adopted methodology - the numerical method and can be used to determine the boundaries of possible soaking and to assess the settlement of individual parts of the foundation and soils of the bases during local soaking.

The use of this method is also possible in the case of non-uniform addition of soil thickness at any moisture range. The task of moistening the strata of subsiding, dense and soft soils is of great practical importance. One of the main reasons causing deformation and destruction of buildings and structures is an increase in the moisture content of the soils of the bases, both during the preparation of the territory and during the operation period due to the destruction of blind areas, trays, canals and water supply networks and the accumulation of water within the boundaries of the compressed soil strata, $t$ that is, in the area of the greatest stress.

Consequently, the nature of the manifestation and development of general deformations, subsidence deformations and even destruction of objects largely depends on the correctly established regularity of soil moistening with their full water saturation. And this, in turn, determines the appropriate methods and principles for calculating structures on collapsible soils, on non-subsiding soils, as well as a set of appropriate measures that would ensure the impossibility of moisture ingress into the zone of compressible soil strata.

Based on the studied theoretical and practical aspects of excessive moisture, the authors identified and studied the peculiarity of the foundations of a residential 9-storey building. Hence, it follows that the condition of the buildings was affected by excessive moisture, as a result of which the building structures received significant damage and displacement of individual elements.

Therefore, one of the solutions to stop the deformation caused by uneven subsidence of the building is repair work or replacement of sewer and water pipes, as well as restoration of the blind area and basement parts of the building. To reduce the cost of restoring damaged structures of the inspected building, you can use the methodology developed in the article [16].

\section{Summary}

Inspection of the building made it possible to reveal the following: cracks and cracks in individual structures with widths reached an opening from several millimeters to several centimeters; places of local soaking of the soils of the bases under the building, caused by leaks of communications and violation of the integrity of the blind area around the building. 
On the basis of a numerical method, the problem of the distribution of moisture in depth with local soaking was solved and the character of soil moisture was obtained at different depths with different degrees of moisture and soil characteristics.

Analysis of information sources, factual material based on the survey results and theoretical solutions made it possible to identify the reasons for the appearance of cracks in the building structures and cracks between its individual elements: deformations are caused by uneven building settlements as a result of local soaking.

\section{References}

1. V.I. Krutov, A.M. Galushko, A.A. Rudenko, Study of the influence of the rise in the level of groundwater on the subsidence of built-up territories, Industrial construction and engineering structures, 3, 27 ... 28 (1972).

2. V.I. Krutov, About initial (critical) humidity of loess soil. Foundations, foundations and soil mechanics, Materials of the III All-Union meeting (Kiev, Budivelnik, 1971).

3. V.I. Krutov, A.S. Kovalev, V.A. Kovalev, Design and construction of foundations and foundations on collapsible soils (Publishing house of the Association of Civil Engineering Universities (ASV), Moscow, 2013).

4. Methodological guide for the design of foundations on collapsible soils (Moscow, 2020).

5. V.A. Galushko, Mathematical modeling of point humidification, Collection of scientific works "Prospective problems of engineering science" (Edited by Academician MJA, Ph.D., prof. Bolshakova VI Dnepropetrovsk, GAUDEAVUS) 4 248-252 (2002).

6. DBN B.2.1-10-09 Foundations of buildings and structures. Change No. 1. (Kiev, 2011).

7. A.I. Havrylyak, I.B. Bazarnyk, R.I. Kinash, M.V. Kotov, M.R. Bilsky and others, Technical operation, reconstruction and modernization of buildings: Textbook (Lviv Polytechnic National University Publishing House, Lviv, 2006).

8. V.T. Grozdov, Technical inspection of building structures of buildings and constructions (KN + Publishing House, St. Petersburg, 2001).

9. B.I. Dalmatov, Mechanics of soils, foundations and foundations (including a special course in engineering geology): Textbook. 3rd ed. (Lan, 2017).

10. E.S. Dzektser, Flooding process - forecast and engineering protection, Industrial and civil engineering 10, 16-18 (2003).

11. D. Goncharenko, I. Shumakov, O. Starkova, A. Aleinikova, R. Mikautadze, Methodological and computer-based support for choosing under ground utility networks renovation method, 7th International Scientific Conference "Reliability and Durability of Railway Transport Engineering Structures and Buildings" (Transbud, Kharkiv, 2018).

12. V. Fomin, M. Bekirova, M. Surianinov, I. Fomina, Nonlinear Dynamic Analysis of a Reinforced Concrete Frame by the Boundary Element Method, Materials Science Forum, 6th International Conference "Actual Problems of Engineering Mechanics" (APEM 2019), ISSN:1662-9752. 968, 383-395 (2019).

13. S. Neutov, M. Sydorchuk, M. Surianinov, Experimental Studies of Reinforced Concrete and Fiber-Reinforced Concrete Beams with Short-Term and Long-Term Loads, Materials Science Forum. 6th International Conference "Actual Problems of Engineering Mechanics" (APEM 2019), ISSN:1662-9752. 968, 227-233 (2019). 
14. M. Surianinov, D. Lazarieva, I. Kurhan, Stability of orthotropic plates, E3S Web of Conferences 166, 06004 (2020).

15. M. Surianinov, S. Neutov, I. Korneieva, Comparative analysis of strength and deformation of reinforced concrete and steel fiber concrete slabs, E3S Web of Conferences 166,06003 (2020).

16. O. Meneylyuk, A. Nikiforov, I. Meneylyuk, Transport construction costmanagementbyrationalorganizational and technological solutions, EasternEuropean Journal of Enterprise Technologies, 3/3 (105) 16-24 (2020). (https://doi.org/10.15587/1729-4061.2020.205117). 